\title{
It Isn't What I Thought It Would Be: The Hesburger Case
}

Ronald J. Patten, DePaul University, USA

Hannu Seristo, Helsinki School of Economics, Finland

\begin{abstract}
A person's initial exposure to another country can be an unnerving experience. This case provides such an exposure and gives substantial information about the country being visited. In addition, a specific business practice is experienced and compared with a similar, but not identical experience in the home country.
\end{abstract}

Keywords: Finland, Canada, travel, business practices, culture

\section{INTRODUCTION}

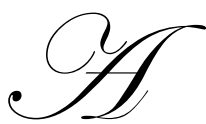

\section{AN OPPORTUNITY}

Sigmund Abernathy operates a travel agency in Ottawa, Ontario, in Canada. Being an imaginative entrepreneur, he is constantly looking for new ways to gain customers. Recently, his thoughts had turned to Finland.

Since Canada is a northern country, Sigmund reasoned that Canadians would be comfortable traveling to other northern countries. Further, since some of his customers had enjoyed traveling to and in Alaska, in the United States, he thought they would enjoy traveling in Finland as well. After all, Alaska and Finland tend to both be located a reasonably similar distance from the equator.

Before going any further with his idea, Sigmund decided to do some research about Finland. Here is what he found: Finland is a country of only 5 million people who speak a rather strange language, Finnish. The country is quite wealthy, ranking $12^{\text {th }}$ in the world in terms of GDP per capita measured in Purchasing Power Parity terms. The main exports are electronics, mostly related to mobile telephony, that make about 25 per cent of exports - not surprising for the home country of Nokia. Another 20 per cent of exports is made of paper and other wood based materials and goods, building on the vast forest resources of the country, which is large in area $(80 \%$ of the size of Ontario), boasting 188 thousand lakes. Along with other Nordic countries, Denmark, Sweden, and Norway, Finland is one of the so-called welfare states; measured in the Gini index, the income distribution in Finland is the $9^{\text {th }}$ most even in the world, Canada ranks $28^{\text {th }}$ and the United States $74^{\text {th }}$. Seeing this from another perspective, the low-skill workers in the country are among the best paid and thus the most expensive in the world, whereas the highest educated employees like researchers for the electronics industry are relatively low paid. Finland is also one of the highest taxed countries in the world: tax revenues are 44 per cent of the GDP when the corresponding figure for Canada is 33 and for the U.S. 27 per cent. The structure of the income distribution and the high level of taxes has made Finland a self-service society where, somewhat paradoxically, the unemployment level is high, currently about 9 per cent.

Having gathered all of this information, Sigmund spent considerable time studying it. Finally, he believed he had a reasonable understanding of what Finland must be like. 
He decided to test his idea by making a trip to Finland himself. Rather than signal his intention to Finnish hotels and tour companies, he decided to make the trip independently. Many of his customers prefer independent travel rather than organized tours and they enjoy sampling a variety of hotels, bed and breakfasts, and restaurants. Additionally, by traveling independently, the customers could set their own itinerary as to places to visit, timing of the visit, duration of the visit, etc.

With his possible strategy set in his mind, Sigmund flew from Ottawa to New York and caught a Finnair flight to Helsinki. Once at the Helsinki-Vantaa Airport in Helsinki, he noticed that a variety of car rental companies were doing business. "This is wonderful", he thought, "because Canadians like to shop for the best deal." He decided to rent from Avis for an attractive weekend rate of 99 euros plus unlimited mileage. One of the provisions of the rental agreement required him to return the automobile with a full tank of gasoline (petrol).

As Sigmund drove around Southern Finland, he was impressed with the beauty of the numerous lakes and the vast forests. In fact, he was so impressed that he drove the automobile for more kilometers than he had originally planned. He was amazed at how well his rental car, a Nissan Micra, handled the roads. Further, he was pleased at how many kilometers he had driven. However, he noticed the fuel gauge showed the tank was about 1/3 full. Consequently, he had to find a place where he could add gasoline to the tank.

While searching for a gasoline station where he could purchase fuel for the automobile, Sigmund began to think about a calculation he would make. Kilometers driven divided by liters placed in the tank should yield the kilometers driven per liter of gasoline consumed. Fortunately, both Canada and Finland used the liter measurement so his potential customers should be very comfortable with that aspect of their Finnish holiday experience. While thinking of gasoline consumption he could not help but gulp when he saw the posted price of gasoline --- $1.37 €$ per liter for grade 95E. "Renting a gas-guzzling SUV in this country is for sure not to be recommended", he thought. Maybe I should calculate the cost per kilometer driven so that my customers will be fully informed as to what to expect, he thought. While mulling over this question in his mind, he arrived at the gas station.

Sigmund had noticed some gas pumps outside a Hesburger outlet. Hesburger is a Finnish chain that operates altogether 220 fast food outlets mostly in Finland and some in the neighboring countries.. "Wonderful," he thought, "I can put gasoline in the tank and, while I am stopped, I can have something to eat and drink. It is wonderful that the Finnish hamburger companies also own gasoline stations. Now, I can depend on the reputation of the hamburger company to treat me fairly and to charge a reasonable price for the gasoline"

Driving up to the gasoline pumps, he noticed the word "Automatia" "Oh" he thought, "this must be just like our automatic gasoline pumps in Canada". However, he noticed there was one slot for credit cards and another for cash. He tried his Visa, Mastercard, American Express, and Diners credit cards, but for some reason each one was rejected. Being a resourceful Canadian, he decided to put cash in the machine. He noticed that the machine would only accept 5, 10, 20, and 50 euro notes. Now, came the question, how much should he put in the machine?

No problem, thought Sigmund. In Canada, we receive change either from the machine or from the people working within the adjoining shop. He assumed the Hesburger food outlet was the shop involved with the petrol pumps since the name Hesburger was displayed overhead in each place. "If I put too much money in the machine I will receive change" he said to himself. So, he put a 50 Euro note into the machine.

Following the instructions that appeared on the machine, all of which were printed in English, he began putting gasoline into the car. At $38.77 €$, the pump stopped and it appeared the tank was full. Knowing you could squeeze the handle for a few more drops, he managed to put $39.18 €$ in the tank. Replacing the cap on the gas tank, he went to the machine to get his change. To his surprise, he found that there was no place on the machine from which to receive change. Undaunted, he strode confidently into the Hesburger food shop to receive his change.

Explaining his situation to the worker at the counter, Sigmund was met with a surprised look. The worker stated what she perceived to be the situation. "You put a $50 €$ note in the machine, you put $39.18 €$ worth of petrol in the car's tank, and the tank is now full." "Yes", said Sigmund, " that is the situation exactly". Sigmund was not certain, but he thought he detected a slight look of amusement on the face of the counter worker. The worker 
excused herself and walked out of sight. "Probably getting my change" thought Sigmund. To his astonishment, when the worker returned, she indicated nothing could be done. "What" Sigmund sputtered, "but the company received more money than I received gasoline in return". The worker only nodded her head and shrugged her shoulders.

Sigmund was beside himself. His experience had made him so angry that he could not think clearly. He even forgot why he had come to Finland in the first place. All he could think about was what had happened to him at the gasoline stop. He even forgot to order something to eat and drink from the Hesburger shop.

As Sigmund drove back toward the airport from which he had rented the car, his mind began to regain some clarity. "Gee", he thought, "how many kilometers did I drive and how many liters of gasoline did I purchase when I filled the tank? When I get back to Canada I will do some searching on the Internet to see what Nissan says is a reasonable expectation for mileage when driving the Micra". Unfortunately, his mind then switched back to the gasoline purchase experience and he forgot about the mileage calculation.

The more he thought about it, the more upset he became once again. "Why in Canada, that clerk at the hamburger stand would have tried very hard to get my change for me. After all, she is working for the same company that sells the gasoline. What kind of service do these Finns provide? Maybe I should call one of my professor friends at the Ivey School of Business in Canada and suggest that they come over to Finland to teach these people something about service".

As Sigmund returned the automobile to the rental agency, he went to the Tax Free window at the airport to begin the process of receiving his VAT refund. Although that situation should have given him some pleasure, since it reduced the cost of some of the goods he had purchased in Finland, his mind kept returning to the gasoline purchase incident.

\section{CONCLUSION}

Often, a person's initial experience in a country will color that person's perception of the entire country. As a novice international traveler, one must guard against such tendencies.

\section{AUTHOR INFORMATION}

Dr. Ronald J. Patten is Dean and Professor Emeritus at DePaul University. A CPA, he was the first Director of Research at the Financial Accounting Standards Board. He has served as Visiting Professor in Malaysia, Singapore, Japan, Russia, Germany, Finland, Denmark, and at the University of Minnesota, the University of Texas-Austin, and Northeastern University. Patten is a Past National President of Beta Gamma Sigma, the scholastic honor society for business administration and a past member of the Board of Directors of the Assembly for Advancement of Collegiate Schools of Business, the international accrediting organization for business studies.

Dr. Hannu Seristö is professor of International Business at the Helsinki School of Economics (HSE) in Finland. He is Vice Rector of HSE and also Vice President of the new Aalto University in Finland. His research work has been in the areas of European Union and its impact on business, international competitive strategies and international marketing management. He teaches courses such as International Marketing Management, and Doing Business in the European Union. The EU course has been chosen Course of the Year in Europe by the Community of European Management School (CEMS) in 2007 and 2008. In addition to his academic positions he has management work experience in companies such as Finnair, McKinsey \& Co. and Suunto.

\section{TEACHING NOTES}

This case can be used in the early portion of an International Business course where the instructor is interested in discussing the differences between cultures. The case will have the greatest potential impact on those students who have never visited another country. There is ample opportunity to discuss expectations on the part of a person visiting another country for the first time. To what extent should someone carry experiences from their home 
country to another country? Here, the instructor can initiate a discussion into the rationale or reason behind certain behavior patterns and how the mores and folkways of a society are carried from generation to generation. An assignment may be given in which the students are asked to conduct research in an effort to discover what are the behavioral expectations underlying employment in Finland. Once having discovered the behavioral expectations in Finland, the students may be asked to contrast their discovery with the behavioral expectations in their home country. They can be asked as to whether their discovery can lead to generalizations about expected behavior in other countries. In the case of Finland, a relevant factor is that the Finnish culture differs from that in North America, for instance when it comes to service provision. First of all, seriousness of a person is highly appreciated in the Finnish society, it is associated with wisdom and dependability. But seriousness, which shows as very little talk and no smiles, should not be taken as impoliteness, even if it appears as such particularly to those who are used to North American friendliness (whether sincere or artificial) in services. Moreover, the egalitarianism in the Finnish society is very strong, i.e. "no person is better than the other one", leading sometimes to a low level of services in terms of friendliness. This is supported also by the studies by Hofstede, showing a low "Power Distance" in Finland. Perhaps it is partly this egalitarian view that has turned Finland into a self-service society.

In an Economics course or an Operations Management course, the case may be used to initiate a discussion about relative labor costs in different countries. This discussion, in turn, may lead to a further discussion about how the labor cost structure leads to patterns of behavior for the workers in that country. The case can be a starting point for discussion about income distribution and its effect on worker behavior. In Finland the high cost of blue collar labor and the very high level of taxation has led to a situation where all those services where a human component is significant are very expensive and often automated as far as possible. So, firms try to minimize the number of personnel. An example of that is the fact that in Helsinki, the capitol with more than half a million inhabitants, there are perhaps only three cafes where customers are served to the table - all the rest are self-service facilities. Even with this high level of self-service, Finland is a high-cost country where goods and services are significantly higher than in the other European Union countries on average.

For those instructors looking for a case with possible use in an Accounting course, a suggested topic for discussion is the separate entity assumption ----does Hesburger own both the hamburger stand and the gas station or are they owned by separate entities that happen to be operating at the same location? In this case the answer is the latter. Another possible discussion topic is Sigmund's expenditure for the gasoline. If the expenditure is considered material, it requires the expense to be separately disclosed. This leads to a discussion as to whether this is a special event that is either unusual or reoccurring or whether it is an extraordinary event that is both unusual and nonrecurring. The answer will have an impact on the financial statement disclosure for the entity that owns and operates the gas station. This provides a relatively simple introduction to the topic of disclosure in the income statement. That discussion can be expanded to include earnings per share calculations and their disclosures. In essence, a relatively simple incident can provide a launching point for an in-depth discussion if such is desired by the instructor. In addition to discussing special events and extraordinary events and the implications of each type on financial statement disclosure, the instructor may initiate a discussion of the subject of materiality and how it may be applied to this situation. Gross profit and the ratios that can be calculated using that element, fit neatly into this case. The gasoline station company has a boost in its gross profit since it obtains revenue in this situation with no accompanying increase in cost of goods sold. The instructor now has a springboard from which to launch into a discussion of variable costs and contribution margin if one is so inclined.

Those instructors teaching Business Law may use the case to discuss Sigmund's possible recourse and how it may vary from country to country. This can lead to a further discussion of comparative Business Law.

The case, although reasonably straight-forward, has its greatest potential as a launching pad for in-depth discussion on a number of topics. Those suggested in this teaching note are merely suggestions and by no means constitute an exhaustive listing. 